\title{
The effectiveness of Stepping Stones Triple $P$ parenting support in parents of children with borderline to mild intellectual disability and psychosocial problems: a randomized controlled trial
}

\author{
Marijke Kleefman ${ }^{1 *}$, Daniëlle EMC Jansen ${ }^{1,2}$, Roy E Stewart ${ }^{1}$ and Sijmen A Reijneveld ${ }^{1}$
}

\begin{abstract}
Background: Children with borderline to mild intellectual disability (BMID) have been shown to be at increased risk for psychosocial problems. The presence of these psychosocial problems leads to parenting stress. Stepping Stones Triple P (SSTP) is a parenting support program to support parents with children with BMID and psychosocial problems. The aim of this study was to evaluate the effectiveness of SSTP compared to Care as Usual (CAU) in reducing psychosocial problems in children with BMID.

Method: We conducted a randomized controlled trial in the Northern provinces of the Netherlands. Parents of children aged 5 to 12 with borderline (IQ 70 to 85 ) or mild (IQ 70 to 50) ID and psychosocial problems were invited. Psychosocial problems were identified using the Strengths and Difficulties Questionnaire (SDQ) parent report $(\geq 14)$. Measurements were assessed before the intervention (T0), immediately after the intervention (T1) and after a follow-up of six months (T2). SSTP takes 8 to 10 individual sessions of 40-90 minutes, provided over 10 to 12 weeks. CAU concerned any service, except SSTP. Primary outcomes were the child's psychosocial problems (SDQ parent and teacher forms and the Eyberg Child Behavior Inventory, ECBI). Secondary outcomes were parenting stress (Parenting Stress Index, PSI) and parenting skills (Alabama Parenting Questionnaire, APQ).

Results: In total 209 parents of children aged 5 to 12 with BMID were allocated blindly to either SSTP $(n=111)$ or CAU $(n=98)$. In the intention to treat analyses, SSTP achieved no significantly better effect than CAU for the SDQ parent report, the ECBI and the APQ on the short- and long- term. In the short term, SSTP was significantly more effective than $\mathrm{CAU}$ for the SDQ teacher report $(\mathrm{B}=-2.25,95 \% \mathrm{Cl}-3.79$ to -0.71$)$ and the PSI $(B=-7.06,95 \% \mathrm{Cl}-12.11$ to -2.01). For both SDQ teacher report and PSI, there was no statistically significant effect in the long term. Dropout from SSTP was considerable (49\%), with the effects being solely found in the adherent SSTP subgroup.
\end{abstract}

Conclusions: SSTP had some short-term advantages over CAU, but not in the longer term.

Trial registration: Dutch Trial Register NTR2624. Registered 26 November 2010

Keywords: Borderline to mild intellectual disability, Children, Psychosocial problems, Parenting support, Randomized controlled trial

\footnotetext{
* Correspondence: m.kleefman@umcg.nl

${ }^{1}$ Department of Health Sciences, University Medical Center Groningen,

University of Groningen, PO Box 196, 9700 AD Groningen, the Netherlands

Full list of author information is available at the end of the article
} 


\section{Background}

Psychosocial problems, such as problems with behavior and emotions, occur frequently in children with borderline to mild intellectual disability (BMID) [1]. Prevalence rates vary widely, from $30 \%$ to more than $60 \%$ [1-3]. The combination of psychosocial problems and BMID is likely to restrict school and social participation and can also limit occupational opportunities in the post-school period [4]. Furthermore, raising a child with BMID and psychosocial problems is likely to lead to parenting stress [5-7]. The child's psychosocial problems and parenting stress are likely to exacerbate each other over time [8].

Improving parenting skills using parenting interventions has been shown to lead to great reductions in both the child's psychosocial problems and the parents' parenting stress [9]. A promising parenting programme is Stepping Stones Triple P (SSTP). SSTP is part of the Australian Triple P, Positive Parenting Programme. This program is a family intervention that aims to prevent and reduce severe behavioral, emotional and developmental problems in children with all kinds of disabilities, including BMID, by enhancing the knowledge, skills and confidence of parents $[10,11]$.

Although SSTP seems promising, evidence of its effectiveness is very scarce. Results of some studies in Australia showed significant improvements in child behavior and parenting styles in different target populations of pre-school children, children with autism or other developmental disabilities [12-15]. In addition, a Dutch non-randomized, non-controlled study of SSTP has shown positive effects on psychosocial problems in children, on parenting skills, family functioning and parental wellbeing [16]. However, these findings have been challenged on the basis of a number of weaknesses. First, the Australian developers were involved in all the effectiveness studies. Second, these studies had small sample sizes or comprised children without BMID. Furthermore, many of these studies did not compare the effects with other interventions offered simultaneously or Care as Usual (CAU) [17].

Accordingly, convincing evidence of the effects of individual SSTP in children with BMID and their parents is still lacking. Therefore, the aim of this study was to assess the effectiveness of the SSTP parenting support program in reducing psychosocial problems in children with BMID compared to CAU.

\section{Methods}

\section{Research design}

The study was conducted as a randomized controlled trial with three assessments: before the intervention (T0), immediately after the intervention (T1) and six months later (T2), and is reported following the CONSORT guidelines [18]. Full details of the trial protocol can be found elsewhere [19]. The Medical Ethics Committee of the University Medical Center Groningen approved the study design. Parents participated voluntarily in this study, having signed to attest their informed consent and were free to leave the study at any time.

\section{Study setting and participants}

We obtained a sample of parents using a two-step process. First, through schools, parents of children 5- to 12-years old with borderline (IQ 70 to 85 ) or mild (IQ 70 to 50) intellectual disability (ID), living in the four northern provinces of the Netherlands (Groningen, Friesland, Drenthe and a part of Overijssel) were invited to complete a screening measurement (that is, T0) about their child's psychosocial problems and their parenting skills. In the Netherlands, children 5- to 12-years old with BMID mainly attend three types of schools for special educational needs, known in Dutch as SBO, REC3 and REC4. SBO (Speciaal Basis Onderwijs: special primary education) includes children with borderline intellectual disabilities (IQ 70 to 85), learning difficulties and/or behavior difficulties. REC 3 (Regional Expertise Center cluster 3) is a type of school for children with physical disabilities, mild to severe intellectual disabilities (IQ $<55$ or IQ 56 to 70 with other severe disabilities) and/or chronic diseases. REC 4 (REC cluster 4) serves children with psychiatric and/or behavioral disorders with borderline ID (IQ 70 to 85) or children with psychiatric and/or behavioral disorders without ID (IQ $>85)[20,21]$. All the participating parents completed the Strengths and Difficulties Questionnaire (SDQ) about their child's psychosocial problems [22,23]. To increase response rates, schools sent a reminder to all parents who did not respond within four weeks and each school published a newsletter on the study, based on information provided by the researchers.

In the second step of sampling, eligible parents of children with a clinical Total Difficulties Score (TDS) on the SDQ parent form of 14 or higher were invited by the researcher to participate in the intervention study. If necessary, we offered assistance in completing the screening measurement (T0). Moreover, parents completed the second and third questionnaires during a visit by a research assistant, who was thereby able to provide assistance.

\section{Exclusion}

At the first step of the sampling process, the screening exclusion criteria were: (1) the child lived in residential care (except foster care); (2) the parents were unable to speak Dutch; (3) information about the child's IQ was not available; or (4) the parents lived outside the research area. At the second step, the intervention selection, the exclusion criteria were: (1) a brother or sister 
(with a higher SDQ-TDS) was already participating in the study: and (2) the parents were receiving treatment for parenting skills or other treatment that potentially conflicted with SSTP.

\section{Intervention}

SSTP aims to enhance the knowledge, skills and confidence of parents to prevent behavioral, emotional and developmental problems in children with disabilities, including BMID [11]. SSTP is based on seven key steps to positive parenting: (1) ensure a safe, interesting environment; (2) create a positive learning environment; (3) use assertive discipline; (4) have realistic expectations; (5) take care of oneself as a parent; (6) family adaptation to having a child with a disability; and (7) be part of the community. The last two principles are specific extensions of Triple P for Stepping Stones, targeting the specific problems of raising children with a disability [13].

SSTP requires eight to ten individual sessions of 40 to 90 minutes each, divided over four modules and provided over a period of ten to twelve weeks. The first module, 'Assessment', consists of two sessions of about 60 to 90 minutes each. In this module, the parents formulate hypotheses about the problems and make relevant causes and factors clear. The second module, 'Positive Parenting, also consists of two sessions of about 60 to 90 minutes. These sessions introduce parenting strategies to the parents. The third module, 'Practice', consists of three sessions of about 40 to 60 minutes each. In these sessions, parents practice their newly acquired parenting strategies and receive support. The final module, 'Planned Activities Training', consists of three sessions of about 60 to 90 minutes. In these sessions, parents are assisted in the practical implementation of the strategies [11].

In this study, eight SSTP health care professionals delivered SSTP. These professionals were all SSTP accredited, that is, they completed training by an accredited SSTP trainer and an accredited SSTP trainer provided periodic supervision. The professionals worked for a Dutch healthcare organization that specialized in clients with disabilities (Dutch: MEE). These professionals did not provide CAU.

\section{Care as Usual}

Parents assigned to the control condition, CAU, could use any service except SSTP. The main types of service used were Practical Pedagogical Family Support (PPG), Video-home training (VHT), Intensive Pedagogical Homecare (IPT) or Intensive Orthopedagogical Family Care (IOG), but individual psychiatric or psychological care for the child was also sought and in some cases no care at all.

\section{Primary outcomes}

The primary outcomes of the study were child's psychosocial problems, measured with the SDQ on the parent and teacher forms and with the Eyberg Child Behavior Inventory (ECBI). The SDQ consists of questions on four subscales with five items each: emotional symptoms, conduct problems, hyperactivity and peer relationship problems. Each item can be scored on a 3 -point scale $(0=$ not true, 1 = somewhat true and 2 = certainly true), yielding a TDS ranging from 0 to $40[22,23]$. The ECBI consists of 36 items in which parents rate how often behavior occurs. Each item can be scored on a 7-point scale ( 1 = 'never' to 7 = 'always'). The sum of these scores yields a sum score on the ECBI ranging from 36 to 252 [24,25].

\section{Secondary outcomes}

The secondary outcomes were parenting practices and stress. Parenting practices were measured using the Alabama Parenting Questionnaire (APQ), short version [26]. This consists of 35 items on parenting practices, in four subscales: parental involvement, positive parenting, poor monitoring and inconsistent discipline. Each item can be scored on a 5-point scale ( 1 = 'never' to 5 = 'always') which yields a sum score on the APQ ranging from 35 to 175 [26,27].

Parenting stress was measured using the short Dutch version of the Parenting Stress Index (PSI) [28]. This questionnaire consists of 25 statements about experiences related to child characteristics, parent characteristics and situations that are directly related to the role of being a parent. Each item can be scored on a 6-point scale $(1=$ totally disagree to $6=$ totally agree $)$ which yield together a sum score on the PSI ranging from 25 to 150 [28].

\section{Background characteristics}

Background characteristics concerned the gender and age of the child, ethnicity (both Dutch or one or both non-Dutch), parental education, parental employment and family composition. Parental education was categorized as: 1) low education: elementary or lower levels of secondary education; 2) middle: higher levels of secondary education or intermediate vocational education; 3) high: higher vocational education and university education. Parental employment was categorized as 1) yes: if at least one parent worked more than 12 hours a week and 2) no: if both parents together worked fewer than 12 hours a week. Family composition was categorized as 1) two biological parents and 2) other: one parent, coparents, adoption and foster parents.

The treatment integrity was measured by the number of sessions attended by the parents. SSTP was completed adequately if the family had attended at least five sessions. 


\section{Sample size}

The parental SDQ-TDS served as the primary outcome measure for determining the sample size needed. For a three-point decrease in the SDQ-TDS, given a standard deviation (SD) for the SDQ of six points (that is, an effect size of 0.5), at alpha $=0.05$ (two-sided) and beta $=0.20,63$ children needed to be included in each group (SSTP and CAU). With adjustment for an estimated 'loss to followup' of $40 \%, 210$ children needed to be included in the study, 105 children in each treatment condition.

The prevalence rate of SDQ-TDS $\geq 14$ in BMID children not under current treatment for their mental health problems was estimated at $55 \%$ [1]. Therefore, $(2 \times$ $105) / 55 \%=381$ children with BMID, 5- to 12-years old, were required. Accounting for $30 \%$ refusal to participate at that step and 10\% incomplete SDQs, 635 parents were need to complete the SDQ at the first step of the selection procedure.

\section{Randomization}

Eligible individuals were randomized per center in each of the four participating centers (Groningen, Friesland, Drenthe and Overijssel) in mixed blocks of four and six to prevent unequal randomization within the centers [29], using a computer-generated randomization algorithm. If parents were randomized to SSTP, the intervention started within four weeks of administering the screening measurement (T0). In the first part of the study the randomization ratio was 1 to 1 . After one year of inclusion, this was adapted to 2 SSTP to 1 CAU because of a relatively high drop-out rate in the SSTP group.

\section{Blinding}

Parents were allocated blindly to either SSTP or CAU. Furthermore, the teachers did not know who was participating in which group. The SSTP trainers could not be blinded to the treatment status during the intervention. Last, the research assistant was also not blinded to treatment status.

\section{Statistical analyses}

First, we described the flow of participants - parents in a diagram [30].

Second, we described the baseline characteristics of the parents in each research group. The differences between the groups were tested using Pearson Chi-square tests for categorical variables and one-way analysis of variance (ANOVA) for continuous variables.

Third, we compared the effectiveness of SSTP with CAU on the primary and secondary outcomes by assessing the effects of SSTP compared to CAU using mixed model techniques. In this analysis, the individual measurements were the first level and the child was the second. The effects on the SSTP group compared to the
CAU group were assessed as regression coefficients (B) with $95 \%$ confidence intervals (CI) in the short term (that is, T0 to T1) and in the long term (that is, T0 to T2) adjusted for age and gender. First, we performed an intention to treat (ITT) analysis, in which all randomized parents were analyzed regardless of whether or not they completed the intervention and any post-treatment questionnaire, with the last observation carried forward. Because of the high dropout rate in the SSTP group, this group was also split into SSTP completed and SSTP not completed for additional analyses.

Finally, all the parents who completed the screening measurement and at least one post-measurement were included in the complete case analyses. All analyses were performed using SPSS Statistics version 20.0.

\section{Ethical permission}

Ethical permission for this study was obtained from the Medical Ethics Committee of the University Medical Center Groningen (METc2010.203; ABR: NL29554.042.10). All participants gave informed consent before taking part in the study.

\section{Results}

The study was performed between October 2010 and October 2013. Figure 1 shows the flow of participants through the study. A total of 49 schools (75\% of those invited) agreed to participate. The main reasons for school non-participation were participating in other research, being under increased monitoring by the superintendent of schools and having too little time. Non-participating schools did not differ from participating schools in terms of location (rural or urban) and type. A total of 1,027 parents completed the screening measurement (T0).

After selection and randomization, 209 parents were randomized to either CAU $(n=98)$ or SSTP $(n=111)$ at the second step of the sampling procedure. All initial 209 parents were included in the ITT analysis. For complete case analyses, data on at least one post-treatment measurement was available for 201 parents ( $n=105$ in SSTP and $n=96$ in CAU). Of the SSTP group, data were available on 56 parents who adequately completed SSTP (that is, attended at least five sessions) and on 49 parents who did not adequately complete SSTP (that is, attended fewer than five sessions).

\section{Baseline data}

At baseline, SSTP and CAU groups did not differ regarding any background variable other than parental employment; fewer parents were unemployed in the SSTP group compared to the CAU group $(P<0.05)$. There were no significant differences between the two groups for any of the outcome variables at baseline. This indicates that the randomization procedure generally resulted in two similar 


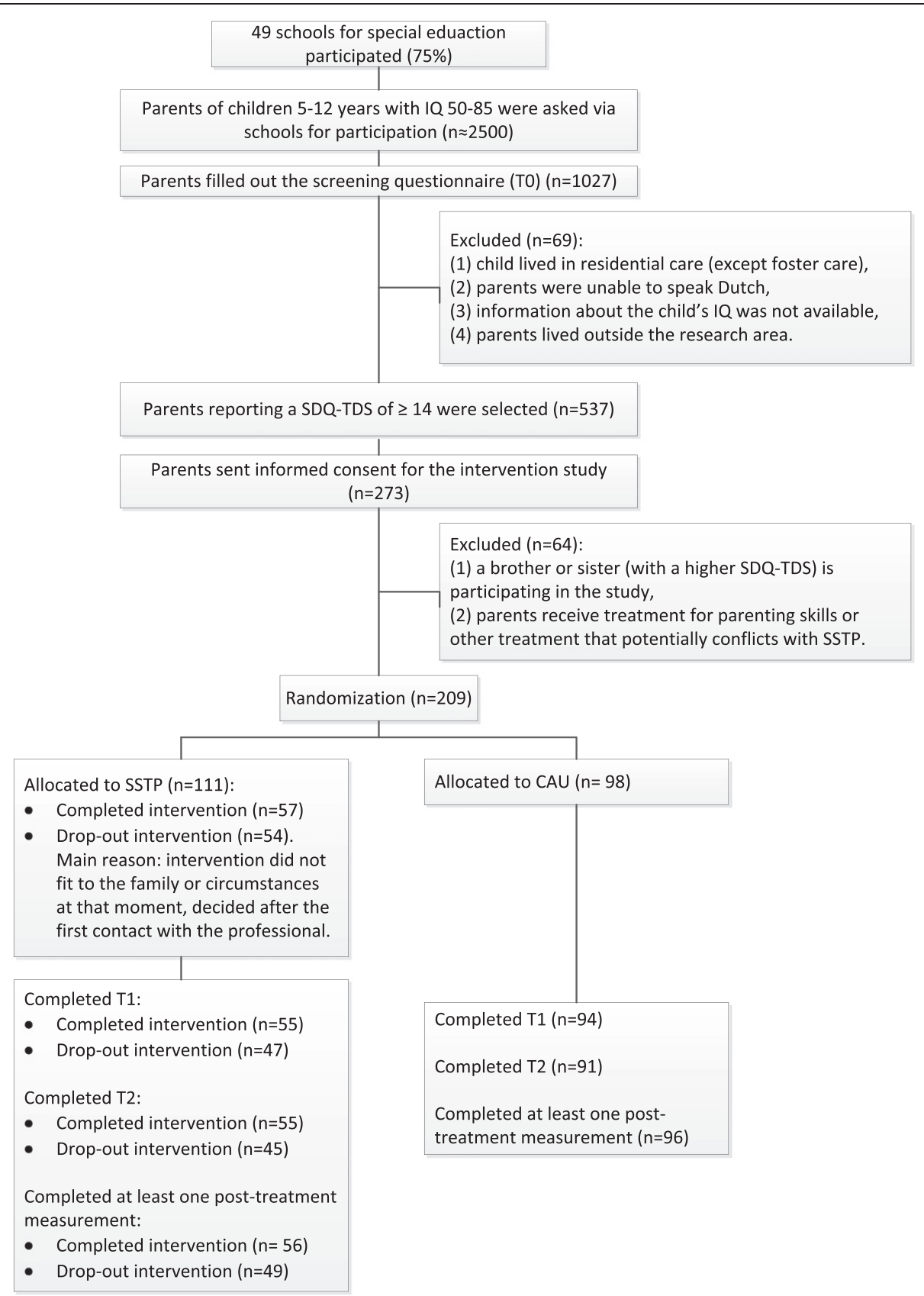

Figure 1 Flow of participants through the study.

groups. Furthermore, SSTP completed, SSTP not completed and CAU groups did not differ from each other either in terms of any of the background or outcome variables. Table 1 shows the baseline characteristics of the parents in all the groups.

\section{Treatment integrity}

The number of sessions parents who were randomized to SSTP received varied from zero to ten. In the SSTP completed group, the number of sessions varied from five to ten. None of the parents in the SSTP group received additional support during the period of receiving SSTP. Fifty-four of the 111 parents were in the SSTP not completed group (49\%). Of these 54 parents, 34 did not start the intervention after the intake and 20 parents did not finish before completing at least five sessions. Their reasons for dropout included family circumstances (divorce, financial problems or sickness), starting another comparable parenting support intervention, parental expectations that the intervention would be too intensive, 
Table 1 Baseline characteristics (mean (SD) or \%) of participants by treatment group ( $n=209$ )

\begin{tabular}{|c|c|c|c|c|c|c|}
\hline \multirow[t]{2}{*}{ Characteristics } & \multicolumn{3}{|c|}{ SSTP } & \multirow[t]{2}{*}{ CAU } & \multirow[t]{2}{*}{$P$-value ${ }^{a}$} & \multirow[t]{2}{*}{$P$-value } \\
\hline & Completed & Not completed & Total SSTP & & & \\
\hline Number & 57 & 54 & 111 & 98 & & \\
\hline \multicolumn{7}{|l|}{ Child } \\
\hline Age of the child & $9.70(2.07)$ & $10.13(1.60)$ & $9.91(1.86)$ & $9.65(2.01)$ & 0.337 & 0.319 \\
\hline Gender of child (boys) & $64.9 \%$ & $50.0 \%$ & $57.7 \%$ & $58.2 \%$ & 0.941 & 0.282 \\
\hline Ethnicity Dutch & $94.7 \%$ & $94.4 \%$ & $94.6 \%$ & $99.0 \%$ & 0.082 & 0.212 \\
\hline \multicolumn{7}{|l|}{ Parents } \\
\hline Mother's education (medium-high) & $61.4 \%$ & $48.2 \%$ & $54.9 \%$ & $54.0 \%$ & 0.322 & 0.386 \\
\hline Father's education (medium-high) & $56.6 \%$ & $42.0 \%$ & $49.5 \%$ & $44.7 \%$ & 0.408 & 0.488 \\
\hline Employed (>12 hours/week) & $92.0 \%$ & $93.8 \%$ & $92.2 \%$ & $83.3 \%$ & 0.042 & 0.123 \\
\hline \multicolumn{7}{|l|}{ Family } \\
\hline Two-parent family & $68.4 \%$ & $69.8 \%$ & $69.1 \%$ & $64.3 \%$ & 0.463 & 0.754 \\
\hline \multicolumn{7}{|l|}{ Pre-measures } \\
\hline SDQ_p (score 0-40 /tds) & $19.00(4.33)$ & $19.52(4.33)$ & $19.25(4.32)$ & $19.84(4.00)$ & 0.313 & 0.486 \\
\hline SDQ_t (score 0-40 /tds) & $14.96(7.05)$ & $13.98(6.18)$ & $14.46(6.61)$ & $13.50(6.69)$ & 0.340 & 0.498 \\
\hline ECBI (score 36-252 /ss) & $131.30(27.64)$ & $119.80(25.61)$ & $125.70(27.17)$ & $127.67(27.19)$ & 0.605 & 0.072 \\
\hline PSI-s (score 25-150 /ss) & $79.40(24.79)$ & $68.64(24.64)$ & $74.22(25.19)$ & $72.82(23.95)$ & 0.682 & 0.065 \\
\hline APQ (score 35-175 /ss) & $99.72(7.89)$ & $98.89(8.10)$ & $99.32(7.97)$ & $98.80(8.39)$ & 0.651 & 0.783 \\
\hline
\end{tabular}

lack of time, or the parents' non-recognition of their child's psychosocial problems. Of these 54 parents, 25 (46\%) started another parenting intervention. In the CAU group, 36 parents indicated that they received parenting support such as phone contact with a professional, a home visit by a professional, intervention 'Intensive Pedagogical Homecare (IPT)', or intervention 'Intensive Orthopedagogical Family Care (IOG)'. In this CAU group, 62 parents did not receive parenting support during the study period.

\section{Effects on primary and secondary outcomes}

Table 2 presents the effects based on the ITT analyses of all 209 parents regarding SSTP compared to CAU in the short term (T0 to T1) and in the long term (T0 to T2). All analyses were adjusted for gender and age. Regarding the SDQ parent form, SSTP did not differ significantly from CAU in the short term. Parents in the SSTP group scored lower on the SDQ in the short term than parents in the CAU group ( $\mathrm{B}=-0.05,95 \% \mathrm{CI}-1.23$ to 1.12 ); this difference was not statistically significant. The differences between the two groups remained non-significant in the long term ( $\mathrm{B}=0.06,95 \% \mathrm{CI}-1.12$ to 1.24 ). Furthermore, no differences were found on the ECBI between the two groups in the short and long term. On the SDQ teacher form, teachers in the SSTP-group did differ significantly from those in the CAU group after completion of the intervention (short-term). Teachers in the SSTP group scored children lower on the SDQ than teachers in the CAU group in the short term $(B=-2.25$, $95 \%$ CI -3.79 to -0.71$)$. However, no significant differences between SSTP and CAU were found on the SDQ teacher form in the long term.

Regarding the secondary outcome parenting stress (PSI), the SSTP and CAU groups differed significantly after completion of the intervention (that is, short-term). Parents in the SSTP group scored lower on the PSI than parents in the CAU-group in the short term $(\mathrm{B}=-7.06,95 \% \mathrm{CI}-12.11$ to -2.01). However, no significant differences were found on the PSI in the long term. Finally, no differences were found between the SSTP and CAU groups in either the short and long term on the APQ.

Second, effects of time were analysed. In both the CAU-group and the SSTP-group, the PSI decreased significantly over time $(P=0.009)$. On the primary outcomes, SDQ parent and teacher version and ECBI, and on the secondary outcome APQ we found no statistically significant differences over time.

Third, we repeated all analyses in three groups to compare the effects of both SSTP completed and SSTP not completed with CAU in the short and long term. With respect to the SDQ parent and teacher form, neither SSTP completed nor SSTP not completed resulted in statistically significant different outcomes compared 
Table 2 Raw means at T0, T1 and T2 and regression coefficients based on intention to treat analyses with mixed models $(n=209)$

\begin{tabular}{|c|c|c|c|c|c|c|c|c|}
\hline \multirow[t]{2}{*}{ Outcome } & \multirow[t]{2}{*}{ Group } & \multirow{2}{*}{$\begin{array}{l}\text { T0 (Baseline) } \\
\text { Mean (SD) }\end{array}$} & \multirow{2}{*}{$\begin{array}{l}\text { T1 (three months } \\
\text { or immediately } \\
\text { after intervention) } \\
\text { Mean (SD) }\end{array}$} & \multicolumn{2}{|c|}{$\begin{array}{c}\text { Difference in } \\
\text { improvement T0 to T1 } \\
\text { between SSTP and CAU }\end{array}$} & \multirow{2}{*}{$\begin{array}{l}\text { T2 (six months } \\
\text { after intervention) } \\
\text { Mean (SD) }\end{array}$} & \multicolumn{2}{|c|}{$\begin{array}{c}\text { Difference in } \\
\text { improvement T0 to T2 } \\
\text { between SSTP and CAU }\end{array}$} \\
\hline & & & & $\mathrm{B}(95 \% \mathrm{Cl})^{\mathrm{b}}$ & $P$-value ${ }^{\mathrm{b}}$ & & B $(95 \% \text { Cl) })^{b}$ & $P$-value ${ }^{b}$ \\
\hline \multirow[t]{4}{*}{ SDQ_p ${ }^{c}$} & SSTP & $19.23(4.38)$ & $17.28(5.64)$ & $-0.05(-1.23 ; 1.12)$ & 0.927 & $17.31(5.62)$ & $0.06(-1.12 ; 1.24)$ & 0.916 \\
\hline & SSTP-C & $18.98(4.36)$ & $16.98(5.88)$ & $-0.29(-1.70 ; 1.12)$ & 0.689 & $16.60(5.57)$ & $-0.27(-1.68 ; 1.14)$ & 0.706 \\
\hline & SSTP-nc & $19.51(4.43)$ & $17.64(5.40)$ & $0.19(-1.25 ; 1.63)$ & 0.794 & $18.18(5.62)$ & $0.44(-1.02 ; 1.89)$ & 0.557 \\
\hline & $\mathrm{CAU}$ & $19.85(4.00)$ & $17.93(5.34)$ & & & $18.01(5.12)$ & & \\
\hline \multirow[t]{4}{*}{$S D Q \_t^{c}$} & SSTP & $14.52(6.70)$ & $13.96(6.50)$ & $-2.25(-3.79 ;-0.71)$ & 0.004 & $13.09(5.12)$ & $-1.10(-2.65 ; 0.46)$ & 0.165 \\
\hline & SSTP-C & $14.96(7.05)$ & $14.46(6.98)$ & $-2.16(-4.04 ;-0.28)$ & 0.025 & $13.61(4.67)$ & $-1.39(-3.28 ; 0.50)$ & 0.149 \\
\hline & SSTP-nc & $14.05(6.34)$ & $13.43(6.01)$ & $-2.34(-4.22 ;-0.47)$ & 0.014 & $12.46(5.63)$ & $-0.80(-2.71 ; 1.11)$ & 0.410 \\
\hline & $\mathrm{CAU}$ & $13.59(6.66)$ & $14.60(6.46)$ & & & $13.33(7.19)$ & & \\
\hline \multirow[t]{4}{*}{$\left.E C B\right|^{c}$} & SSTP & $126.36(27.60)$ & $113.85(28.03)$ & $-4.71(-10.05 ; 0.63)$ & 0.084 & $114.37(27.94)$ & $-3.83(-9.20 ; 1.55)$ & 0.163 \\
\hline & SSTP-C & $131.90(27.49)$ & $116.62(27.76)$ & $-8.83(-15.22 ;-2.44)$ & 0.007 & $116.84(26.84)$ & $-6.15(-12.55 ; 0.24)$ & 0.059 \\
\hline & SSTP-nc & $120.02(26.59)$ & $110.54(30.48)$ & $-0.37(-6.86 ; 6.13)$ & 0.912 & $111.36(29.25)$ & $-1.38(-7.98 ; 5.21)$ & 0.680 \\
\hline & $C A U$ & $127.63(27.35)$ & $120.51(24.55)$ & & & $118.07(2.77)$ & & \\
\hline \multirow[t]{4}{*}{ PSI-s ${ }^{d}$} & SSTP & $74.68(25.71)$ & $66.67(24.65)$ & $-7.06(-12.11 ;-2.01)$ & 0.006 & $66.57(26.37)$ & $-3.19(-8.28 ; 1.89)$ & 0.217 \\
\hline & SSTP-C & $79.34(25.01)$ & $68.35(22.35)$ & $-10.42(-16.46 ;-4.37)$ & 0.001 & $69.47(26.65)$ & $-4.62(-10.67 ; 1.43)$ & 0.134 \\
\hline & SSTP-nc & $69.25(25.70)$ & $64.62(27.31)$ & $-3.45(-9.63 ; 2.74)$ & 0.274 & $63.02(25.88)$ & $-1.69(-7.96 ; 4.58)$ & 0.596 \\
\hline & $C A U$ & $73.14(24.02)$ & $72.46(22.93)$ & & & $68.14(23.31)$ & & \\
\hline \multirow[t]{4}{*}{$A P Q^{d}$} & SSTP & $99.54(7.95)$ & $99.10(9.17)$ & $-1.27(-3.52 ; 0.98)$ & 0.267 & $101.21(10.87)$ & $1.23(-1.03 ; 3.49)$ & 0.286 \\
\hline & SSTP-C & $99.89(7.05)$ & $98.65(7.52)$ & $-1.68(-4.37 ; 1.02)$ & 0.223 & $101.59(11.55)$ & $1.30(-1.40 ; 4.00)$ & 0.346 \\
\hline & SSTP-nc & $99.14(8.12)$ & $99.63(10.87)$ & $-0.84(-3.59 ; 1.90)$ & 0.546 & $100.78(10.17)$ & $1.13(-1.65 ; 3.91)$ & 0.423 \\
\hline & CAU & 98.58 (8.33) & $99.20(9.21)$ & & & $98.26(9.75)$ & & \\
\hline
\end{tabular}

${ }^{\mathrm{a}}$ Raw mean scores on the different outcome measurements; ${ }^{\mathrm{b}} \mathrm{B}$ for SSTP compared to CAU, based on mixed model techniques, expressing differences in change between SSTP and CAU in outcomes - analyses were adjusted for gender and age; ${ }^{c}$ primary outcome; ${ }^{d}$ secondary outcome. APQ, Alabama Parenting Questionnaire; B, Regression Coefficients; CAU, Care as Usual; CI, confidence interval; ECBI, Eyberg Child Behavior Inventory, PSI-s, Parenting Stress Index short version; SD, standard deviation; SDQ_p, Strengths and Difficulties Questionnaire parent version; SDQ_t, Strengths and Difficulties Questionnaire teacher version; SSTP, Stepping Stones Triple P; SSTP-c, Stepping Stones Triple P completed; SSTP-nc, Stepping Stones Triple P not completed.

to CAU after completion of the intervention (T0 to T1) and at the six-month follow-up (T0 to T2). Significant differences were found between the SSTP completed and CAU groups in the short term on the SDQ teacher form, ECBI and the PSI. No differences were found for the other measurements (see Table 2).

Finally, we performed complete case analyses on 201 parents who completed at least one post measurement. These did not reveal any statistically significant differences between the SSTP and CAU groups for any of the outcome measures (results not shown).

\section{Discussion}

This study evaluated the effectiveness of the parenting support program SSTP compared to CAU in reducing psychosocial problems in children with BMID. The parents of children with clinical psychosocial problems (SDQ-TDS 214 ) were included. In both the ITT and complete case analyses, we found significant differences between SSTP and CAU in the short term for the SDQ teacher form and PSI, but not in the long term. We found no significant differences in effects between SSTP and CAU on the other primary or secondary outcomes at either post-intervention measurement.

We found some advantages in the short term for SSTP over CAU, but no advantages in the longer term. These findings contrast with previous studies which found more positive effects for SSTP on a child's psychosocial problems, on parenting skills, family functioning and parental wellbeing [12-16]. Several explanations for this difference in findings can be provided. First, we compared the SSTP with a control group CAU, whereas other studies only compared SSTP with a waiting list group or no control at all $[12-14,16]$. Second, our study included parents from schools for special education who were selected for intervention using a screening measurement for psychosocial problems. Previous studies included parents who were explicitly referred to healthcare because of problems 
experienced in daily life or which focussed on children with specific problems, such as autism or physical disabilities $[12,14-16]$. It is reasonable to expect that the effects of the intervention would be different, because parents in previous studies had already perceived a need for treatment.

Third, other studies which reported the effectiveness of SSTP were either performed by its developers in Australia or had small sample sizes [12-15]. Therefore, those studies should be interpreted carefully due to information and selection bias [31]. Finally, in contrast with other studies, we used an independent data collection process, which meant that parents were asked to complete questionnaires in the absence of the health care professional who was carrying out the intervention. These questionnaires were not specifically developed for or used in the SSTP intervention.

In summary, our study was carried out effectively and designed to a high standard, owing to a sufficient sample size, independent data collection and control group, which strengthens our findings.

\section{Strengths and limitations}

The main strengths of our study have already been indicated. First, randomization prevented selection and allocation bias, meaning that its internal validity is high. Second, we recruited from schools for special education, so the majority of parents of children with BMID were reached [20]. This increases the external validity and generalizability of our results [32]. Third, our study was well powered because the sample size was sufficient. Fourth, our study had a low loss to follow up because parents received assistance by an independent research assistant in completing the questionnaire if they participated in the intervention study. Furthermore, our data collection was fully independent of the intervention itself, to ensure that the overview obtained was more objective and to avoid social desirability bias [17]. Sixth, we had a follow-up measurement six months after the intervention to enable the study of the effects of the SSTP on psychosocial problems over time. A final strength was the use of two informants to measure the child's psychosocial problems (that is, teacher and parent). More informants lead to a better understanding of a child's functioning, because psychosocial problems can be highly situational and differ at school and at home [33-35].

Our study also had an important limitation: there was selective dropout in the intervention group. Of the 111 randomized parents in the SSTP group, only 57 completed the intervention. Parents in the group that completed SSTP reported more baseline problems on the ECBI (child's behavior problems) and the PSI (parenting stress) than parents in the group that did not complete SSTP.

\section{Conclusions}

This study found some effects in the short term but no effects in the long term for SSTP compared to CAU over time and across outcomes. In terms of the child's psychosocial problems at school and the parents' parenting stress, we found significant differences between the SSTP and CAU groups immediately after the intervention. However, we found no differences six-months after treatment for those two outcomes, nor for the other outcomes.

This study had a high drop-out rate in the SSTP group. The reasons for this deserve additional study as SSTP may not fit this population despite being promising in theory. SSTP might be too intense for certain populations, or insufficiently intense because of the number of problems parents have to deal with [36-38]. Another implication for research is to evaluate the costs of SSTP compared to CAU to determine whether implementation of the SSTP yields cost benefits $[39,40]$.

\section{What is already known on this topic \\ Stepping Stones Triple P seems to be a promising intervention for the parents of children with borderline to mild intellectual disability. However, evidence of its effectiveness remained weak. \\ What this study adds \\ This study adds evidence of the effects of SSTP compared with CAU in a randomized controlled trial. Its results show some short-term advantages and no long-term advantages for SSTP compared to CAU over time and across outcomes.}

\section{Abbreviations}

APQ: Alabama Parenting Questionnaire; BMID: Borderline to mild intellectual disability; CAU: Care as Usual; Cl: confidence intervals; ECBI: Eyberg Child Behavior Inventory; ITT: intention to treat; PSI: Parenting Stress Index; REC: Regional Expertise Center; SBO: Speciaal Basis Onderwijs, special primary education; SD: standard deviation; SDQ: Strengths and Difficulties Questionnaire; SPSS: Statistical Package for the Social Sciences; SSTP: Stepping Stones Triple P; TDS: Total Difficulties Score; ZonMW: Netherlands Organization for Health Research and Development.

\section{Competing interests}

The authors declare that they have no competing interests.

\section{Authors' contributions}

SAR and DEMC had the original idea of the project, wrote the proposal and obtained funding for the study. RES assisted MK in performing the data analyses. MK wrote the final manuscript that was discussed, edited and revised by DEMC, RES and SAR. All authors read and approved the final manuscript, have agreed with the decision to publish, had full access to the data, can take responsibility for the integrity of the data and the accuracy of the data analysis and accept full responsibility for the design and the conduct of the study.

\section{Acknowledgements}

We would like to thank MEE, a Dutch healthcare organization in the four northern provinces of the Netherlands and their professionals, schools and teachers, and the parents and children who participated in this study. 


\section{Funding}

A major Dutch non-profit funding body, the Netherlands Organisation for Health Research and Development (ZonMW), financed the study (grant 15700.3001). The authors were independent of the funders and the funders had no role in the project.

\section{Author details}

'Department of Health Sciences, University Medical Center Groningen, University of Groningen, PO Box 196, 9700 AD Groningen, the Netherlands. ${ }^{2}$ Department of Sociology and Interuniversity Center for Social Science Theory and Methodology (ICS), University of Groningen, Grote Rozenstraat 31, 9712 TG Groningen, the Netherlands.

Received: 27 May 2014 Accepted: 25 September 2014

Published online: 28 October 2014

\section{References}

1. Kaptein S, Jansen DE, Vogels AG, Reijneveld SA: Mental health problems in children with intellectual disability: use of the Strengths and Difficulties Questionnaire. J Intellect Disabil Res 2008, 52:125-131.

2. Dekker MC, Koot HM, van der Ende J, Verhulst FC: Emotional and behavioral problems in children and adolescents with and without intellectual disability. J Child Psychol Psychiatry 2002, 43:1087-1098.

3. Tonge B, Einfeld $\mathrm{S}$ : The trajectory of psychiatric disorders in young people with intellectual disabilities. Aust N Z J Psychiatry 2000, 34:80-84.

4. Einfeld SL, Piccinin AM, Mackinnon A, Hofer SM, Taffe J, Gray KM, Bontempo $D E$, Hoffman LR, Parmenter T, Tonge BJ: Psychopathology in young people with intellectual disability. JAMA 2006, 296:1981-1989.

5. Baker BL, Blacher J, Crnic KA, Edelbrock C: Behavior problems and parenting stress in families of three-year-old children with and without developmental delays. Am J Intellect Dev Disabil 2002, 107:433-444.

6. Beck A, Daley D, Hastings RP, Stevenson J: Mothers' expressed emotion towards children with and without intellectual disabilities. J Intellect Disabil Res 2004, 48:628-638.

7. Friedrich WN, Friedrich WL: Psychosocial assets of parents of handicapped and nonhandicapped children. Am J Ment Defic 1981, 85:551-553.

8. Lecavalier L, Leone S, Wiltz J: The impact of behaviour problems on caregiver stress in young people with autism spectrum disorders. J Intellect Disabil Res 2006, 50:172-183.

9. McGillivray JA, McCabe MP: Early detection of depression and associated risk factors in adults with mild/moderate intellectual disability. Res Dev Disabil 2007, 28:59-70.

10. Sanders MR, Bor W, Morawska A: Maintenance of treatment gains: a comparison of enhanced, standard, and self-directed Triple P-Positive Parenting Program. J Abnorm Child Psychol 2007, 35:983-998

11. Sanders MR, Mazzucchelli TG, Studman L: Practitioner's Manual for Standard Stepping Stones Triple P: for Families with a Child Who Has a Disability: 1st ed. Brisbane: The University of Queensland and Disability Services Commission of Western Australia; 2003.

12. Plant KM, Sanders MR: Reducing problem behavior during care-giving in families of preschool-aged children with developmental disabilities. Res Dev Disabil 2007, 28:362-385.

13. Roberts C, Mazzucchelli T, Studman L, Sanders MR: Behavioral family intervention for children with developmental disabilities and behavioral problems. J Clin Child Adolesc Psychol 2006, 35:180-193.

14. Whittingham K, Sofronoff K, Sheffield J, Sanders MR: Stepping Stones Triple $\mathrm{P}$ : an RCT of a parenting program with parents of a child diagnosed with an autism spectrum disorder. J Abnorm Child Psychol 2009, 37:469-480.

15. Whittingham K, Sanders M, McKinlay L, Boyd RN: Interventions to reduce behavioral problems in children with cerebral palsy: an RCT. Pediatrics 2014, 133:e1249-1257.

16. Speetjens P, de Graaf I: Stepping Stones Triple P Opvoedhulp voor ouders van kinderen met een beperking. Evaluatie van een pilot studie [SSTP Support for Parents with a Child with a Disability: Evaluation of a Pilot Study]. Trimbos Instituut: Utrecht; 2010
17. Wilson P, Rush R, Hussey S, Puckering C, Sim F, Allely CS, Doku P, McConnachie A, Gillberg C: How evidence-based is an 'evidence-based parenting program'? A PRISMA systematic review and meta-analysis of Triple P. BMC Med 2012, 10:130-145.

18. Boutron I, Moher D, Altman DG, Schulz KF, Ravaud P: Extending the CONSORT statement to randomized trials of nonpharmacologic treatment: explanation and elaboration. Ann Intern Med 2008, 148:295-309.

19. Kleefman M, Jansen DE, Reijneveld SA: The effectiveness of Stepping Stones Triple P: the design of a randomised controlled trial on a parenting programme regarding children with mild intellectual disability and psychosocial problems versus care as usual. BMC Public Health 2011, 11:676-682.

20. European Commission: Organisatie van het onderwijssysteem in Nederland 2008/2009 [Organisation of the Dutch Education System 2008/2009]. EURYDICE: The Netherlands; 2008

21. Oeseburg B: Prevalence and impact of chronic diseases in adolescents with intellectual disability. PhD thesis. University of Groningen; 2010.

22. Goodman R: The Strengths and Difficulties Questionnaire: a research note. J Child Psychol Psychiatry 1997, 38:581-586.

23. van Widenfelt BM, Goedhart AW, Treffers PD, Goodman R: Dutch version of the Strengths and Difficulties Questionnaire (SDQ). Eur Child Adolesc Psychiatry 2003, 12:281-289.

24. Robinson EA, Eyberg SM, Ross AW: The standardization of an inventory of child conduct problem behaviours. J Clin Psychol 1980, 9:22-28.

25. Burns GL, Patterson DR: Normative data on the Eyberg Child Behavior Inventory and Sutter-Eyberg Student Behavior Inventory parent and teacher rating scales of disruptive behavior problems in children and adolescents. Child Fam Behav Ther 2001, 23:15-28.

26. Shelton KK, Frick PJ: Assessment of parenting practices in families of elementary school-age children. J Clin Child Psychol 1996, 25:317-329.

27. Essau CA, Sasagawa S, Frick PJ: Psychometric properties of the Alabama Parenting Questionnaire. J Child Fam Stud 2006, 15:595-614.

28. de Brock AJ, Vermulst AA, Gerris JR, Abidin RR: NOSI-Nijmeegse Ouderlijke Stress Index, Handleiding experimentele versie [NOSI-Nijmegen Parenting Stress Index, Manual experimental version]. Lisse. the Netherlands: Swets en Zeitlinger; 1992.

29. Creinin MD, Meyn LA, Borgatta L, Barnhart K, Jensen J, Burke AE, Westhoff C, Gilliam M, Dutton C, Ballagh SA: Multicenter comparison of the contraceptive ring and patch: a randomized controlled trial. Obstet Gynecol 2008, 111:267-277.

30. Hopewell S, Hirst A, Collins GS, Mallett S, Yu L, Altman DG: Reporting of participant flow diagrams in published reports of randomized trials. Trials 2011, 12:253-263.

31. Tripepi G, Jager KJ, Dekker FW, Zoccali C: Selection bias and information bias in clinical research. Nephron Clin Pract 2010, 115:C94-c99.

32. Rothwell PM: Factors that can affect the external validity of randomised controlled trials. PLoS Clin Trials 2006, 3:1-5.

33. Achenbach TM, McConaughy SH, Howell CT: Child/adolescent behavioral and emotional problems: implications of cross-informant correlations for situational specificity. Psychol Bull 1987, 101:213-232.

34. De Los RA, Kazdin AE: When the evidence says, "yes, no, and maybe so": attending to and interpreting inconsistent findings among evidencebased interventions. Curr Dir Psychol Sci 2008, 17:47-51.

35. Goodman R, Renfrew D, Mullick M: Predicting type of psychiatric disorder from Strengths and Difficulties Questionnaire (SDQ) scores in child mental health clinics in London and Dhaka. Eur Child Adolesc Psychiatry 2000, 9:129-134

36. Tamm L, Holden GW, Nakonezny PA, Swart S, Hughes CW: Metaparenting: associations with parenting stress, child-rearing practices, and retention in parents of children at risk for ADHD. Atten Defic Hyperact Disord 2012, 4:1-10.

37. Mildon R, Wade C, Matthews J: Considering the contextual fit of an intervention for families headed by parents with an intellectual disability: an exploratory study. J Appl Res Intellect Disabil 2008, 21:377-387.

38. Wade CM, Mildon RL, Matthews JM: Service delivery to parents with an intellectual disability: family-centred or professionally centred? J App/ Res Intellect Disabil 2007, 20:87-98. 
39. Durlak JA, DuPre EP: Implementation matters: a review of research on the influence of implementation on program outcomes and the factors affecting implementation. Am J Community Psychol 2008, 41:327-350.

40. Romney S, Israel N, Zlatevski D: Exploration-stage implementation variation: its effect on the cost-effectiveness of an evidence-based parenting program. Z Psychol 2014, 222:37-48.

doi:10.1186/s12916-014-0191-5

Cite this article as: Kleefman et al:: The effectiveness of Stepping Stones Triple P parenting support in parents of children with borderline to mild intellectual disability and psychosocial problems: a randomized controlled trial. BMC Medicine 2014 12:191.

\section{Submit your next manuscript to BioMed Central and take full advantage of:}

- Convenient online submission

- Thorough peer review

- No space constraints or color figure charges

- Immediate publication on acceptance

- Inclusion in PubMed, CAS, Scopus and Google Scholar

- Research which is freely available for redistribution 